\title{
Production, \\ Income, and Spending Accelerate
}

F OLLOWING A period of mixed performance in the fall, measures of aggregate economic activity have recently indicated strong expansion. Production has increased sharply since the major strikes ended. Private demand has risen, reflecting the recent acceleration of employment and income. The rate of increase of Government spending, although moderated from that of recent periods, has remained well above the trend rate.

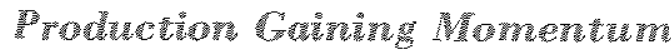

Following a period of strike activity which cut sharply into the recovery of production early in the fall, industrial production increased substantially in November and December. On balance production increased at an 8 per cent annual rate from June to December, with durable products and materials accounting for most of the rapid increase late in the year. Greater automobile output contributed significantly to the growth of production late in the year, and large expansion was also experienced in the production of steel and business equipment. Increased steel production reflects some stockpiling in anticipation of strikes next summer in that industry.

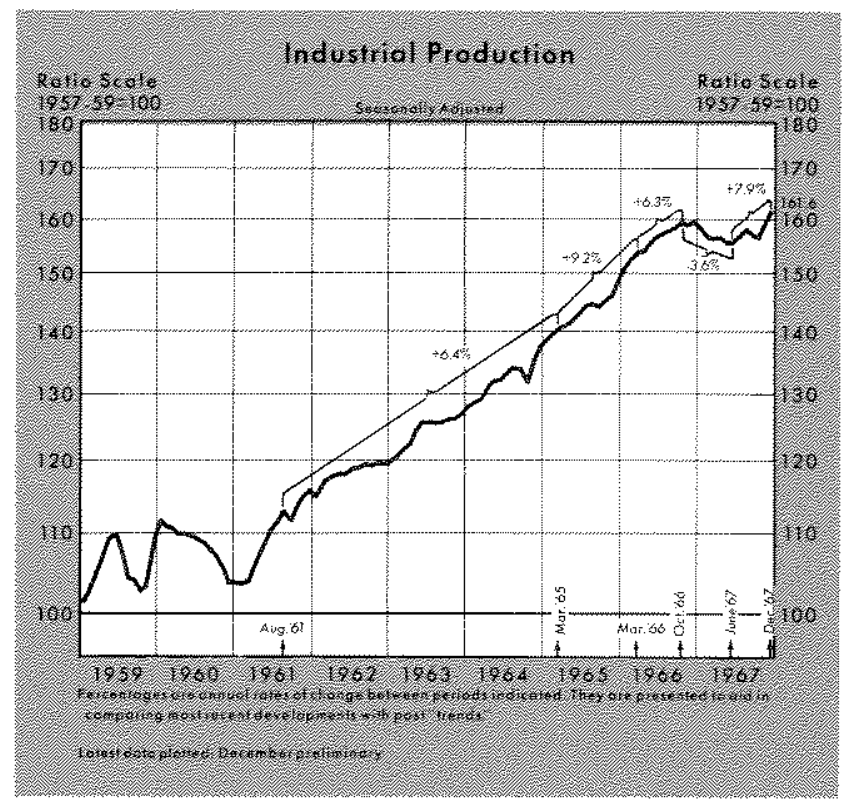

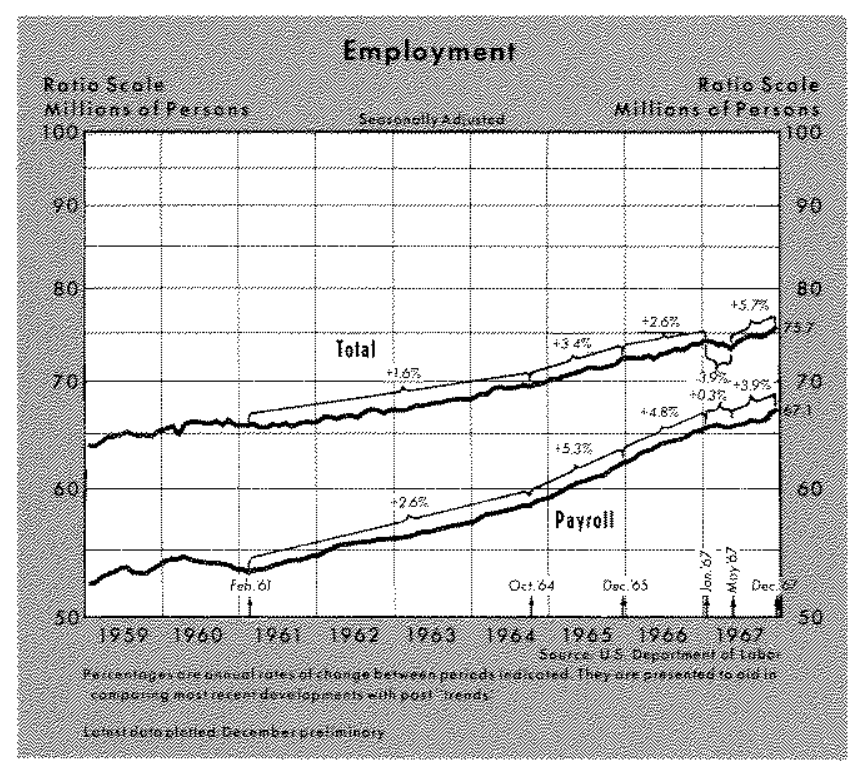

\section{Wmployment and Income Crowng}

Employment increased rapidly late in the year and rose at a 6 per cent rate from the spring of 1967 to the end of the year. Employment in manufacturing, which had declined for most of the year, increased sharply following settlement of the major strikes. Employment in contract construction and wholesale and retail trade showed significant increases from last spring.

Personal income increased rapidly in the last two months of the year and has shown an 8 per cent rate of increase since spring. This compares with a 5 per cent rate of growth in the early part of the year. The potentially strong stimulative effect on spending of the acceleration in income was not fully realized because, relative to past experience, the proportion of after-tax income directed into savings remained high throughout the year. Such sustained behavior on the part of consumers cannot easily be explained, but suggests a cautious outlook due to uncertainty about future prices, Government policy, and international developments.

The disposition of savings showed some change late in the year, as is evidenced by a moderated rate of increase in time deposits at commercial banks. As 
market rates of interest rose to high levels relative to regulated ceiling rates on time deposits, savers, seeking the highest return on their money, tended to increase the direct placement of their funds in the market. Although few banks have actually experienced declines in time deposits, rates of growth have slowed. Increasing direct placement has been becoming more evident as growth rates of large negotiable certificates of deposits, savings deposits, and small savings certificates have slowed considerably from earlier in the year.

\section{Total Demand Accelerabing}

The dollar value of goods and services produced in the economy increased at a 9 per cent annual rate in the second half of 1967 , compared with a 3.4 per cent rate of increase in the first half. Expanded production

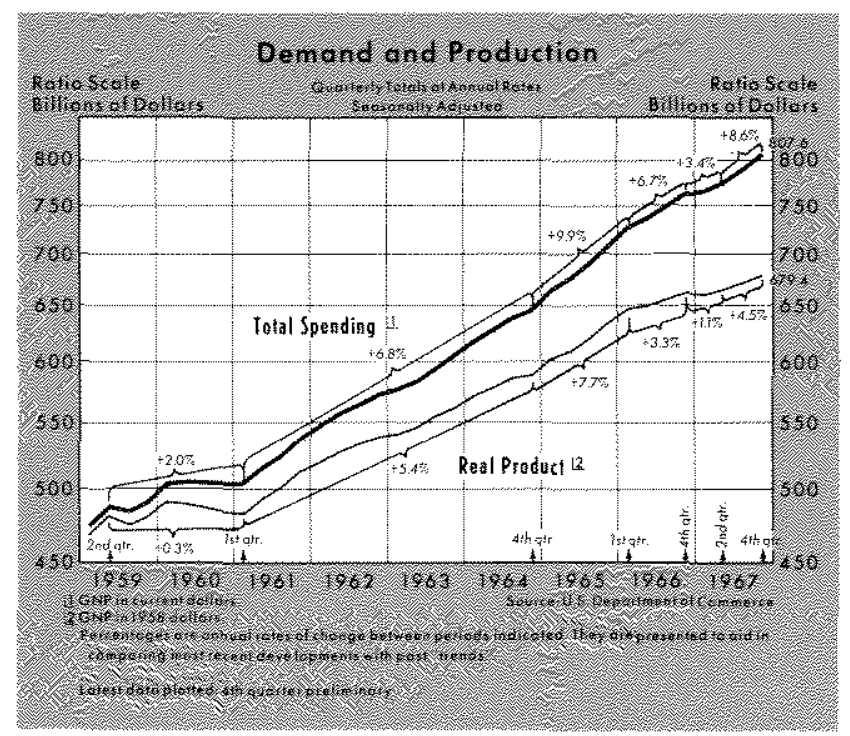

accounted for over half of the accelerated rate, rising at a 5 per cent rate after remaining about unchanged during the first half of the year. Price increases, accounting for the rest of the increased rate, also quick ened from mid-year. The general price level, which had risen at a 2.3 per cent annual rate in the first half, accelerated to a 4.0 per cent rate of increase in the last six months of the year.

The acceleration of total demand was greatest in the business sector. Investment in inventory accumulation, which had declined from an $\$ 18.5$ billion annual rate in the fourth quarter of 1966 to a $\$ 0.5$ billion rate in the second quarter of 1967 , rose to about a $\$ 6$ billion annual rate in the second half of the year and became a strong expansionary force in the economy. Residential construction increased rapidly through the year after declining during most of 1966 . Housing starts totaled 1.3 million units during the year, below the level of

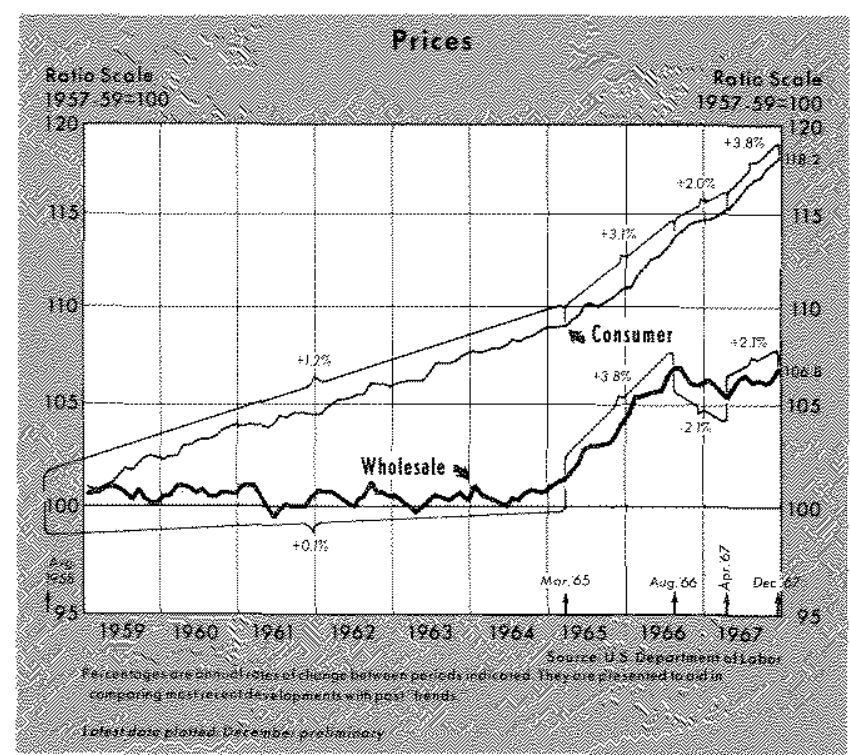

1965 but significantly above the depressed 1.17 million level of 1966.

Consumer spending for durables increased late in the year. Retail sales increased at a 3 per cent rate on balance from May to December, compared with a 5.1 per cent rate of increase from December 1966 to May. The moderated rate over the period was due primarily to sharp declines in sales of durables during the summer and early fall, as strikes affected consumer income and availability of goods. Sales of automobiles and household appliances increased late in the year, as automobiles became more readily available following the strikes and increased residential construction resulted in increased demand for household furnishings.

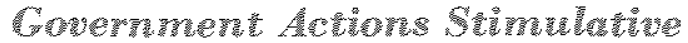

Monetary actions were a major factor contributing

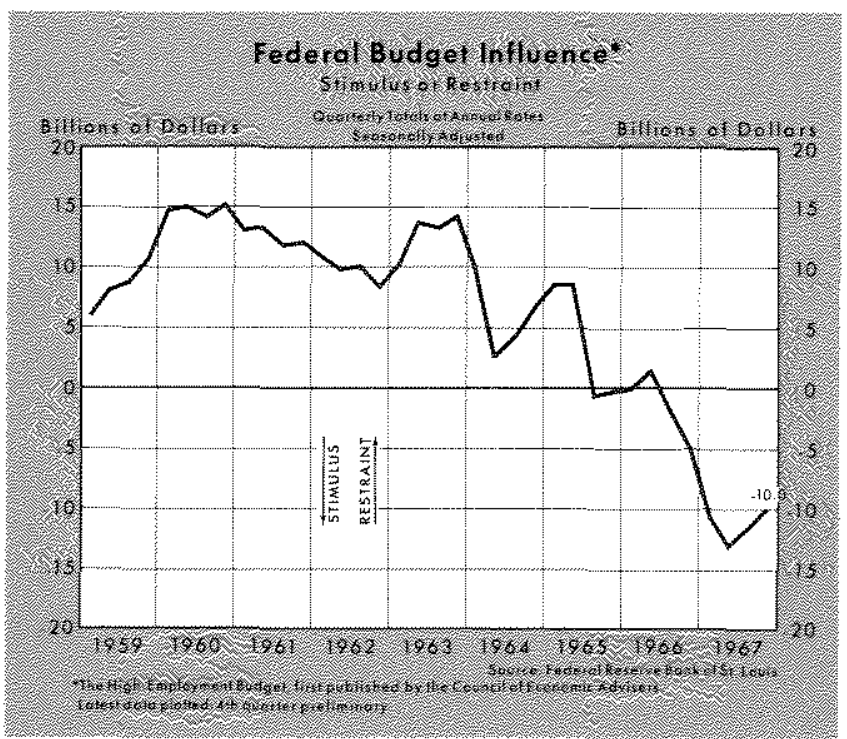




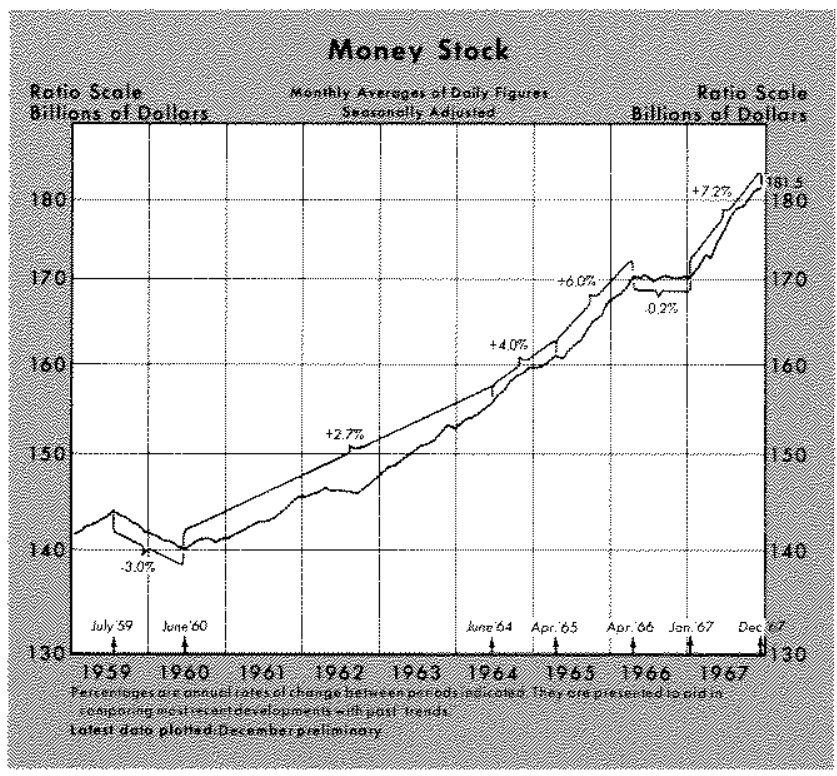

to the acceleration of demand in the second half of 1967. Total reserves of member banks, adjusted for reserve requirement changes, increased at a 10 per cent rate from last January following little change from April 1966 to January. The nation's money stock, defined as private demand deposits and currency in the hands of the public, increased at a 7 per cent rate from last January to the end of the year, compared with no net change over the previous nine months.

Reserve requirements against demand deposits over $\$ 5$ million were raised by the Federal Reserve, effective in January. For reserve city banks the proportion of demand deposits over $\$ 5$ million required to be held in reserve was increased from 16.5 per cent to 17 per cent, effective January 11. For all other banks the requirement was increased from 12 per cent to 12.5 per cent, effective on January 18.

The initial effect of the change in regulations was to increase required reserves by about $\$ 550$ million. Assuming no further System action, this would imply a decrease in bank credit and deposits of over $\$ 3.5$ billion. Such a contraction did not come about, however, as System Open Market purchases and other factors contributed a similar amount of reserves to member banks. The major effect was to transfer about $\$ 550$ million of earning assets from large member banks to the Reserve Banks.

Growth of demand originating in the Government sector moderated in the second half as growth in defense spending slowed. Government purchases of goods and services increased at an 8 per cent annual rate in the second half, compared with a 17 per cent rate of increase in the previous half year. After slowing in the spring, purchases for nondefense purposes accelerated through the rest of the year. Spending by state and local governments increased at a 10 per cent annual rate in the second half, slightly less than in the previous half year.

As measured by the high employment budget, the stimulative force of fiscal actions changed little in the second half. Adjusted for changes in economic activity, Federal expenditures exceeded receipts by about $\$ 11$ billion, approximately the same as in the first half of the year but up from $\$ 3.4$ billion in the second half of 1966.

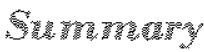

Since late spring economic activity has risen at a rapid rate, with marked acceleration since October. Part of the increase in late fall and early winter was a result of production delayed by strikes, but additional underlying strength is becoming more apparent. Both monetary and fiscal actions of the Government have been the factors contributing to a vigorous growth in spending. Renewed investment in inventory and business plant and equipment suggests that business expectations of future demand have been revised upward. The continued expansion of demand at recent rates is probably unsustainable if balanced economic growth is to be achieved.

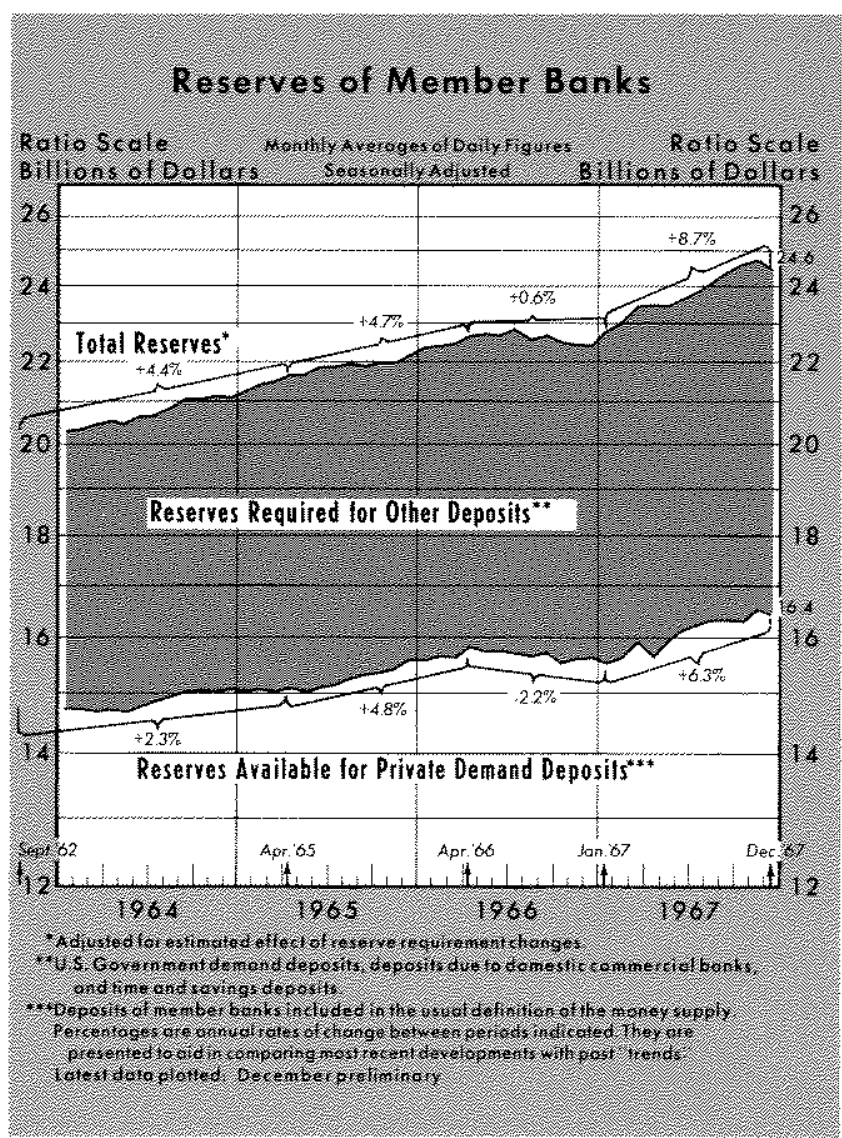

